\title{
Educational perspective for the identification of essential competencies required for approaching patients with COVID-19
}

Mayssoon Dashash,,${ }^{1,2}$ Bashar Almasri, ${ }^{2}$ Eman Takaleh, ${ }^{2}$ Alaa Abou Halawah ${ }^{2}$ and Amal Sahyouni ${ }^{2}$

${ }^{1}$ Damascus University, Damascus, Syrian Arab Republic. ${ }^{2}$ Syrian Virtual University, Damascus, Syrian Arab Republic. (Correspondence to: Mayssoon Dashash: mdashash@yahoo.com, mede_pd@svuonline.org)

\begin{abstract}
Background: Health professionals are at the frontline of the COVID-19 pandemic and are directly exposed to infection hazards. Therefore, they should have the essential competencies for approaching patients.

Aims: The study aimed to identify essential competencies required for approaching patients with COVID-19.

Methods: All postgraduate health professionals at the Syrian Virtual University SVU $(n=28)$ were invited to participate in the study during the Covid-19 lockdown in 2020, resulting in 20 postgraduates accepting. The Delphi technique was adopted for identifying competencies in medical education and a virtual meeting was undertaken through the University Management System in order to provide instruction and create a list of competencies. Competency domains were divided into 'knowledge', 'skills', and 'attitudes' and were classified into four categories: etiology, assessment and diagnosis, management, and prognosis.
\end{abstract}

Results: Fifty-two essential competencies were identified; 7 competencies on etiology, 7 related to assessment and diagnosis, 34 related to management, and 4 related to prognosis

Conclusion: It is hoped that the identified competencies would help health professionals to deliver the best health care for COVI-19 patients, as well as help policy-makers to support comprehensive training programmes that can equip health professionals with the required competencies to fight the pandemic.

Keywords: COVID-19, competencies, health professional, education, Syria

Citation: Dashash M; Bashar A; Takaleh E; Halawah AA; Sayouni A. Educational perspective for the identification of essential competencies required for approaching patients with COVID-19. East Mediterr Health J. 2020;26(9):1011-1017. https://doi.org/10.26719/emhj.20.111

Received: 06/06/20; accepted: 22/07/20

Copyright ( ) World Health Organization (WHO) 2020. Open Access. Some rights reserved. This work is available under the CC BY-NC-SA 3.0 IGO license (https://creativecommons.org/licenses/by-nc-sa/3.o/igo)

\section{Introduction}

On December 12, 2019, health professionals started to investigate patients who developed viral pneumonia, after visiting the Human Seafood Wholesale Market (1). On December 31, 2019, the report published by the Wuhan Municipal Health Commission about viral pneumonia indicated that 27 patients were infected (1). In the first week of January 2020, Chinese officials identified a novel type of coronavirus called SARS-COV-2, which was spread outside of China the following week. On March 2020, the WHO announced COVID-19 as a pandemic (1-3).

It is currently believed that the virus's route of transmission is respiratory droplets (4). Infected patients may have symptoms such as fever (90\%), fatigue and dry cough $(80 \%)$, dyspnea $(20 \%)$, sore throat, headache, or loss of smelling and taste (5). Disease manifestations range from asymptomatic cases to severe pneumonia accompanied by severe respiratory distress and septic shock, followed by multi-organ failure leading often to death (1). According to global statistics, $81 \%$ of patients have a mild infection that spontaneously recovers; $14 \%$ have a severe infection; and $5 \%$ are critical cases that need intensive care and mechanical ventilation $(6,7)$.

Health professionals are directly responsible for facing infected patients and suspected persons. They are at the frontline of the COVID-19 pandemic and are exposed to hazards that put them at risk of infection (8). As of 23 August 2020, there were 23408376 confirmed cases of COVID-19 globally and 809098 deaths; 8499 recorded infections per day, and 15941566 recovered cases (9). Moreover, a recent publication (6 May 2020) by the International Council of Nurses (10) indicated that more than 90 ooo health-care workers around the world were infected with COVID-19, of which 260 nurses had died, amounting to $2.195 \%$ of total confirmed COVID-19 cases (10). In addition, the World Health Organization (WHO) indicated that 194 member states are not providing comprehensive figures on health worker infections while dealing with the unprecedented crisis (11).

It is clear that health professionals should be appropriately prepared to ensure that all necessary preventive and protective measures are taken to minimize occupational safety and health risks. In addition, they should be properly trained to provide the best health care during assessment, triage, and treatment (11). Health professionals should also be successful role performers, since they must possess performance abilities that allow them to operate across a broad range of situations over an extended period of time (12).

Today, competency-based medical education has emerged as a priority issue that should be adopted to overcome the COVID-19 pandemic. The traditional approach that begins with the question "what do health 
professionals need to know about COVID-19?" should be modified to the question "what abilities are needed by health professionals to face COVID-19?" In this regard, an organized framework of competencies should be designed in which the observable abilities of health professionals, integrating multiple components such as knowledge, skills, values and attitudes, can be identified (13-15).

\section{Methods}

This study was undertaken by a research team in the Medical Education Program (MEP), Syrian Virtual University. The MEP is a distance-learning programme designed to enable health professionals to obtain a Master's degree in medical education at the same time as practicing medicine, dentistry, pharmacy or nursing in Syrian health centres or hospitals, which are related to the Syrian Ministry of Health, Ministry of Higher Education, Ministry of Defense or Ministry of Interior. Ethical approval was obtained from the Ethical Committee of the Syrian Virtual University, Damascus, Syrian Arab Republic April 2020.

The Delphi Technique is considered one of the most useful techniques for identifying competencies in medical education $(16,17)$. It has many advantages over other decision-making methods, since it facilitates ownership and increases acceptance of the generated consensus rather than possible bias developed by dominant individuals $(17,18)$. Therefore, the technique was employed to develop consensus about essential competencies required for approaching COVID-19 patients.

All MEP students were invited to take part in this study $(n=28)$. Twenty postgraduates who represent different faculties in the Syrian Arab Republic and different health specializations accepted to participate in this study. During the lockdown, participants were virtually instructed, using the Virtual University Management System to study all recently published protocols and guidelines on COVID-19 by recognized health bodies such as WHO, Centers for Disease Control and Prevention, the UK National Health Service, and Cochrane collaboration (19-22). Advice was also received concerning the methodology for writing competencies and vocabulary to be used to describe functions (18) in order to create the initial list of competencies related to essential knowledge, skills and attitudes required for approaching patients with COVID-19.

To develop a general plan of competencies, participants were divided into three groups corresponding to knowledge, skills, and attitudes domains that can identify competencies for appropriate and safe practice when dealing with COVID-19 (23). To unify the work and style, responses were gathered, reviewed, and modified for each domain by the team leader. Repeated and inappropriate competencies were also deleted or reformulated. A second virtual meeting was undertaken to discuss switching any competency from its domain to another. It was also agreed to cross-match these groups with the classification of required competencies according to etiology, assessment and diagnosis, management, and prognosis of COVID-19. Each member in the meeting was asked to revise the list of competencies in each major group and under each classification separately.

The revised list was then sent to the participants to suggest any additional items or modification that should be considered and to rate each competency on a 4- point Likert scale: 0, 1, 2 and 3 corresponding to 'not important', 'less important', 'important', and 'essential', respectively $(23,24)$.

In the third stage, the resulted list was sent again to all participants. Competencies suggested by at least $80 \%$ of participants were combined and merged. To obtain the weighted response for each competency, the number of responses in each level and the mean score for each competency (o.0-3.0) were calculated $(18,23,24)$. All competencies required for COVID-19 were ranked and the relative importance for each competency was determined.

\section{Results}

The response rate was $71.4 \%$ for invited participants $(n=20)$. The findings indicated 52 essential competencies suggested by at least $80 \%$ of participants required for approaching COVID-19 patients. The competencies for each domain were organized under three major categories including knowledge, skills and attitude, as outlined in Figure 1, which presents the 'Ability' with its purpose, process and commitment as previously documented (25). In addition, four subheadings including etiology, assessment and diagnosis, management, and prognosis were also outlined in Table 1.

The final identified competencies were as follows: 12 knowledge competencies, 20 skills competencies, and 20 competencies related to attitudes. According to competencies classification, 7 competencies were related to etiology, 7 competencies related to assessment and diagnosis, 34 competencies related to management, and 4 competencies related to prognosis.

\section{Discussion}

There is an extensive global effort to provide effective treatment and research for a vaccine to combat COVID-19. For this purpose, numerous scientific papers are published daily (1); however, efforts targeting health professionals exposed daily to the hazards of COVID-19 infection are still limited. To rectify this, it is important that occupational health and safety become a priority and health professionals should be equipped with all essential competencies before duties on the front line of COVID-19 disease response.

This is where the role of medical education needs to be highlighted. It can ensure that all health professionals directly involved in prevention or treatment of COVID-19 pandemic, whether patient intake, screening, inspection, 
Table 1 Essential competencies required for approaching patients with COVID-19

\section{Domain}

Knowledge

Etiology

Assessment \&

Diagnosis

Management

\section{Skills}

Etiology

Assessment \& Diagnosis

Management

Prognosis

\section{Attitude}

Management

\section{Competency}

1. Recognize COVID-19 Epidemiology

2. Differentiate between epidemic, outbreak and pandemic of COVID-19

3. Recognize the virus etiology, origin, incubation period and transmission models

4. Apply the principles of isolation, quarantine, contacts, and contacts tracing

5. Identify high- risk groups of COVID-19 patients

6. Recognize types of different diagnostic tests

7. Identify signs and symptoms of COVID-19

8. Apply infection control and prevention strategies

9. Recognize health and safety of medical equipments

10. Discuss isolation and quarantine periods, isolation conditions

11. Apply therapeutic protocols and empirical drugs

12. List indications and contraindications of medications and procedures

13. Take accurate clinical history

14. Assess the readiness of health facility

15. Perform appropriate medical examination

16. Draw blood samples, nasal swaps and bronchial lavage safely and correctly

17. Screen and triage at all points of access to the health system

18. Interpret results of laboratory tests and radiographic images correctly

19. Provide correct differential diagnosis in each medical case

20. Apply health and safety procedures

21. Educate patients to the extent that they can understand

22. Calculate therapeutic doses accurately

23. Apply treatment in the correct way and time and make appropriate adjustments for each case

24. Use medical equipment and devices for managing patients with COVID-19

25. Appraise and assimilate scientific evidence

26. Provide accurate diagnosis of COVID-19

27. Decide the right time for initiating and finishing treatment

28. Appraise the scientific publications about COVID-19

29. Perform triage and control origin of infection

30. Manage clinical cases according to development and stage and complications

31. Start and terminate isolation precautions when necessary

32. Perform a plan to monitor health care staff who were in contact with definite cases of COVID-19

33. Provide protection measurements for health care workers

34. Demonstrate Professionalism to peers, staff, patients and patient's families

35. Work with health care professional including other disciplines

36. Keep patient safe and protect him/her from harm

37. Demonstrate respect to patients' privacy and confidentiality

38. Maintain patients' dignity during providing health care

39. Show sympathy and compassion to patients

40. Explain all information regarding COVID-19 to community 
Table 1 Essential competencies required for approaching patients with COVID-19 (concluded)

\section{Domain}

\section{Competency}

41. Demonstrate an investigatory and analytic thinking approaches to meet the needs of COVID-19 patients

42. Provide the best health care to patients regardless of age, gender, cultures and economic situations without discrimination

43. Provide spiritual support to patients and suspected infected persons

44. Demonstrate Self-management and self-awareness

45. Develop the required skills to prevent transmission of COVID-19

46. Promote health against COVID-19 and anticipate when priorities should be changed

Management

47. Develop strategies for consultation, collaboration, and referral

48. Provide optimal value care

49. Communicate effectively with patients, their families and colleagues to inform them about case development

50. Show leadership, initiative, optimism, and influence to control disease spread in the most effective manner

51. Work flexibly under stress and under changing conditions and remain calm

52. Apply the national health policy, guidelines and recommendations

testing, transport, treatment, nursing, specimen collection, pathogen detection, pathologic examination or technical personnel, should all have the necessary competencies to deal with this pandemic (2).

Participants were instructed to write competencies required for dealing with COVID-19 in the light of those competencies already constructed for professionals dealing with accidents and emergencies in the United States of America (26), United Kingdom (27) and Canada (28). For example, according to Clerkship Directors in Emergency Medicine (CDEM), six core competencies should be acquired when dealing with COVID-19including patient care, medical knowledge, professionalism, systems-based practice, practice-based learning and improvement, and interpersonal and communication skills (26). In the present study, 52 essential competencies related to ethical behaviour, professionalism, personal development health promotion, disease prevention and management were identified.

To the best of our knowledge, this study is the first that has identified competencies examining knowledge, skills, and attitudes domains and categories, including etiology, assessment and diagnosis, management, and prognosis of COVID-19.

Following studies by George Miller (1990) (29), it is suggested that knowledge, competencies, performances and actions are required for health professionals at the frontline of the COVID-19 pandemic. This study has adopted the hierarchy proposed by Miller whereby three domains of learning competencies - including knowledge (cognitive), skills (psychomotor) and attitude (affective) - have been addressed (29). For example, if the health professionals are in the frontline of the pandemic they should know the etiology of the disease (cognitive domain), should be able to perform physical examination (psychomotor domain), and should have communication and teamwork skills in a trauma situation (affective domain). Health professionals who have the information 'know what' and expertise 'how to' will master the process. Through the skills 'knowing how' and attitudes 'knowing why', health professionals will be encouraged and remain committed to the patient. It is also clear that the unity of knowledge with attitudes can grant them an over-arching sense of purpose in patient care $(25,29,30)$. Union of purpose, process and commitment provides the heath professional with the 'Ability', enabling effective disease control and maintain health and safety of patients and society in general (Figure 1).

The present study is unique in gathering core competencies needed for health-care workers to face COVID-19 patients. In the literature, a previous research article assessing knowledge, skills, and attitudes among 327 health-care workers about COVID-19 at District 2 Hospital in Ho Chi Minh City, Viet Nam (31), found that the majority of health-care workers had good knowledge and positive attitude toward COVID-19. However, researchers also found that the level of learning was lower than expectation. Therefore, they suggested updating knowledge and learning materials about this epidemic and as well as to communicate information to professionals who have a lack of knowledge or were not aware of COVID-19 (31).

Similarly, another study assessed the knowledge, attitude, and practice (KAP) of 1357 health professionals towards COVID-19 across ten hospitals in Henan, China (32). The study addressed the need to understand the KAPs of health workers and possible risk factors in order to deliver the relevant training and policies that can provide protection and decrease occupational exposure during the outbreak (32).

The current study has introduced a novel and practical model for development of training programmes during 
Figure 1 Three components (knowledge, skills and attitudes) that enable competency in health professionals (purpose, process and commitment) when approaching patients with COVID-19

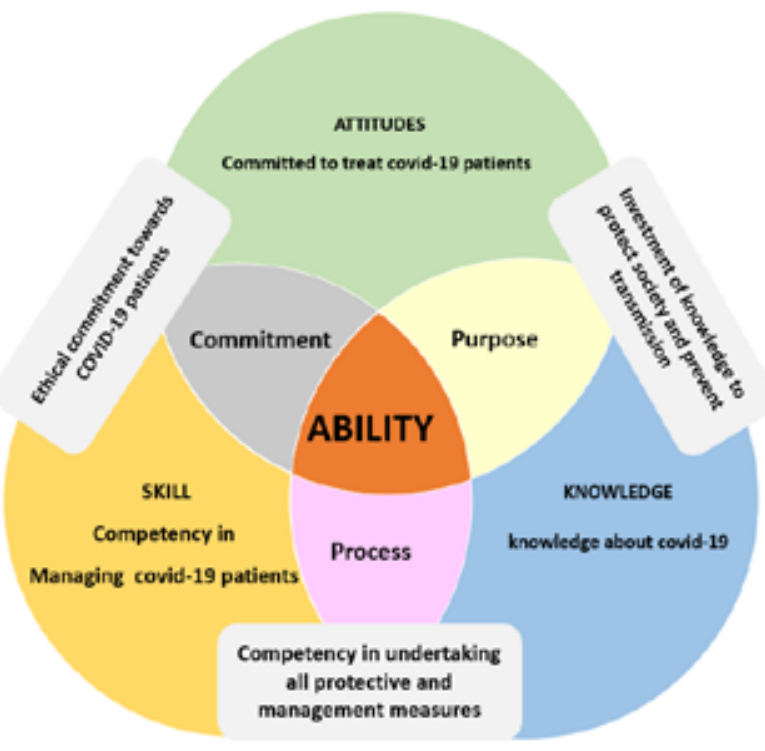

the pandemic. In addition, the consensus of participants upon all points through the Delphi technique increases the reliability and confidence of results, drawing from previous studies used the Delphi method to develop curriculum for undergraduate medical education. For example, Almoallim (2011) (18) determined competencies in undergraduate internal medicine curriculum in Saudi Arabia using the Delphi technique, identifying competencies based on a group (20 clinicians) utilizing textbooks (18). Similarly, Shah et al. (2019) (33) developed a national competency-based diabetes curriculum in undergraduate medical education.

\section{Limitations}

Sample size $(n=20)$ was a limiting factor and an increase in the number of participants would be of critical importance to support our findings. Comprehensive understanding about COVID-19 is still not possible. Specific agreed treatments for COVID-19 patients are not yet fully available. Thus, there remains a concern that these competencies identified might require continuous revision in light of the ongoing understanding of the etiology, assessment and treatment to address the COVID-19 pandemic. Therefore, the present findings should be considered as a baseline for future work that aims to clearly identify competencies that can influence the process of curriculum reform in the Region adopted by schools, and the methods of assessment that can measure the knowledge, skills and attitude of health professionals.

It is hoped that the identified competencies would direct policy-makers to support and organize ad hoc comprehensive training programmes that can equip health professionals with the required knowledge, attitudes and skills competencies to enable them to effectively deal with the pandemic.

\section{Conclusion}

Future training development for health care professionals dealing with COVID-19 patients should consider utilizing the designed list of competencies highlighted in this study to assess and improve competencies.

Funding: None.

Competing interests: None declared.

\section{Perspective pédagogique concernant l'identification des compétences essentielles requises pour aborder les patients atteints de COVID-19}

\section{Résumé}

Contexte : Les professionnels de santé sont en première ligne dans la lutte contre la pandémie de COVID-19 et sont directement exposés aux risques d'infection. Ils doivent donc posséder les compétences essentielles pour aborder les patients.

Objectifs : La présente étude visait à identifier les compétences essentielles requises pour aborder les patients atteints de COVID-19.

Méthodes : Tous les professionnels de santé postuniversitaires de la Syrian Virtual University (Université virtuelle syrienne) ( $\mathrm{n}=28$ ) ont été invités à participer à l'étude lors du confinement pour la COVID-19 en 2020,;20 diplômés ont accepté l'invitation. La méthode Delphi a été adoptée pour identifier les compétences en matière d'éducation médicale et une réunion virtuelle a été organisée par le biais du système de gestion universitaire afin de fournir une instruction et de créer une liste de compétences. Les domaines de compétence ont été divisés en " connaissances », « compétences » et « attitudes » et ont été classés en quatre catégories : étiologie, évaluation et diagnostic, prise en charge et pronostic.

Résultats : Cinquante-deux compétences essentielles ont été identifiées : sept compétences sur l'étiologie, sept sur l'évaluation et le diagnostic, 34 sur la prise en charge et quatre sur le pronostic.

Conclusion : Nous espérons que les compétences identifiées aideront les professionnels de santé à fournir les meilleurs soins de santé aux patients atteints de COVID-19, ainsi que les responsables de l'élaboration des politiques à soutenir des programmes de formation complets susceptibles de doter les professionnels de santé des compétences nécessaires pour lutter contre la pandémie. 


$$
\begin{aligned}
& \text { منظور تعليمي لتحديد الكفاءات الاساسية للتعامل مع مرضى كوفيد-19 } \\
& \text { ميسون دشاش، بشار المصري، آلاء أبو حلاوة، إيان تقالة، أمل صهيوني }
\end{aligned}
$$

الخلفية: يو اجه المهنيون الصحيون في الخطو طا الأولى لمجابهة جائحة كوفيد-19 مخاطر العدوى مباشرة. ومن ثَمَ يجب أن يكون

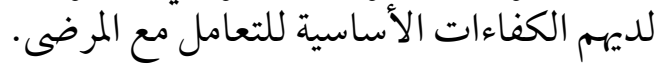
الأهداف: هدفت هذه الدراسة إلى تحديد الكفاءات الأساسية المطلوبة للتعامل مع مرضى كوفيد-19

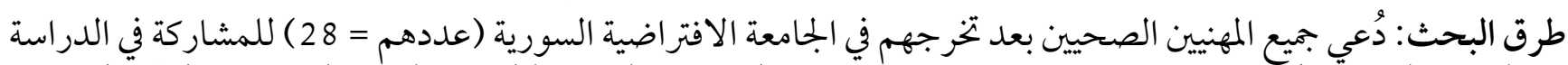

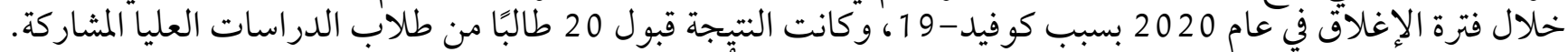

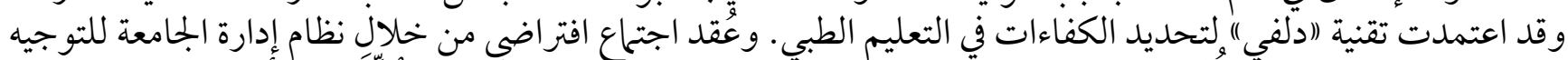

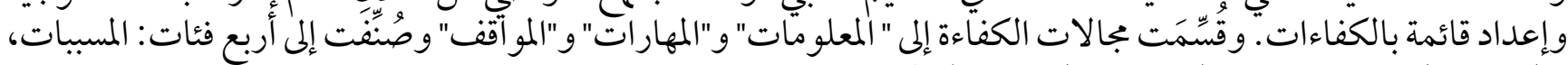

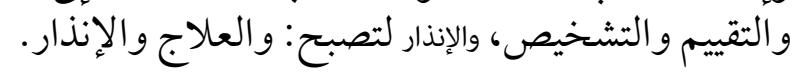

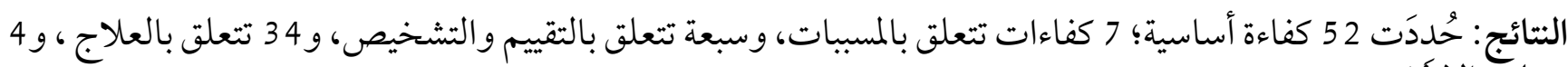
تتعلق بالإنذَار.

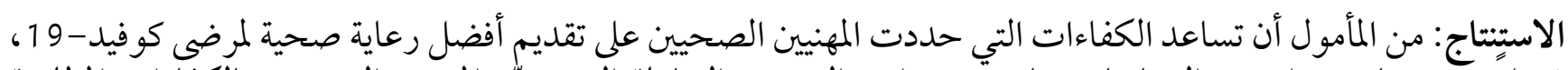

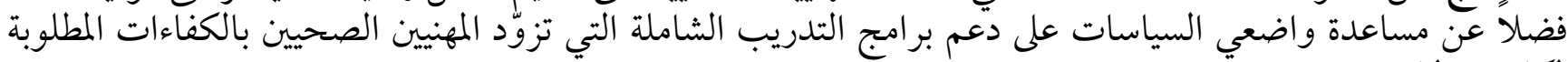
لمكافحة الجلائحة.

\section{References}

1. Kamps BS, Hoffman C. COVID Reference, Steinhäuser Verlag, 3-2020 third edition. (https://amedeo.com/CovidReferenceo3.pdf).

2. Zhu N, Zhang D, Wang W, Li X, Yang B, Song J, et al. A novel coronavirus from patients with pneumonia in China, 2019. N Engl J Medicine 2020;382:727-733. doi:10.1056/nejmoa2001017

3. World health Organization. Virtual press conference on COVID-19. Geneva: World Health Organization; 2020 (https://www. who.int/docs/default-source/coronaviruse/transcripts/who-audio-emergencies-coronavirus-press-conference-full-and-final11mar2020.pdf?sfvrsn=cb432bb3_2, accessed 10 March 10,2020).

4. World health Organization. Modes of transmission of virus causing COVID-19: implications for IPC precaution recommendations. Geneva: World Health Organization; 2020 (https://www.who.int/news room/commentaries/detail/modes-of-transmission-of-virus-causing-covid-19-implications-for-ipc-precaution-recommendations).

5. Chen N, Zhou M, Dong, X, Qu J, Gong F, Qiu YHY, et al. Epidemiological and clinical characteristics of 99 cases of 2019 novel coronavirus pneumonia in Wuhan, China: A descriptive study. Lancet 2020;395:507-513. doi:10.1016/s0140-6736(20)30211-7

6. Wu Z, McGoogan JM. Characteristics of and important lessons from the coronavirus disease 2019 (COVID-19) outbreak in China. JAMA 2020;323:1239-1242. doi:10.1001/jama.2020.2648

7. Jamil S, Mark N, Carlos G. Diagnosis and management of COVID-19 disease. Am J Respir Crit Care Med. 2020;201:P19-P20 doi:10.1164/rccm.2020c1

8. World health Organization. Coronavirus disease (COVID-19) outbreak: rights, roles and responsibilities of health workers, including key considerations for occupational safety and health: Interim guidance. Geneva: World Health Organization; 19 March 2020.

9. Corona virus Worldometer (https://www.worldometers.info/coronavirus/, accessed 23 August, 2020).

10. Mantovani C. Over 90,00o health workers infected with COVID-19 worldwide: nurses group. Reuters, 6 May 2020 (https://www. reuters.com/article/us-health-coronavirus-nurses/over-900oo-health-workers-infected-with-covid-19-worldwide-nurses-groupidUSKBN22I1XH, accessed 15 May 2020).

11. World Health Organization. Coronavirus disease 2019 (COVID-19): situation report, 121. Geneva: World Health Organization; 2020 (https://www.who.int/docs/default-source/coronaviruse/situation-reports/20200520-covid-19-sitrep-121. pdf?sfvrsn=c4bezec6_2, accessed 15 May 2020).

12. Harden RM, Crosby JR, Davis MH. AMEE Guide No. 14: Outcome-based education: Part 1-An introduction to outcome-based education. Med Teach. 1999;21:1.

13. Hand JS. Identification of competencies for effective dental faculty. J Dent Educ;70:937-946.

14. Tonni I, Oliver R. A Delphi approach to define learning outcomes and assessment, Eur J Dent Educ. 2012:1-8. 
15. Jason R. Frank, Linda S. Competency-based medical education: theory to practice, Med Teach. 2010;32:638-645, doi:10.3109/01421 59X.2010.501190

16. De Villiers MR, de Villiers PJ, Kent AP. The Delphi technique in health sciences education research. Med Teach. 2005;27:639-643.

17. Dunn WR, Hamilton DD, Harden RM. Techniques of identifying competencies needed of doctors. Med Teach. 1985;7:15-25.

18. Almoallim H. Determining and prioritizing competencies in the undergraduate internal medicine curriculum in Saudi Arabia. East Mediterr Health J. 2011;17:656-662. https://doi.org/10.26719/2011.17.8.656

19. World Health Organization. Coronavirus disease (COVID-19) pandemic. Geneva: World Health Organization; 2020 (https:// www.who.int/emergencies/diseases/novel-coronavirus-2019, accessed 15 May 2020).

20. NHS England and NHS Improvement Coronavirus, Specialty guides for patient management secondary care (https://www. england.nhs.uk/coronavirus/secondary-care/other-resources/specialty-guides/, accessed 15 May 2020).

21. Centers for Disease Control and Prevention (CDC). Information for healthcare professionals about coronavirus (COVID-19). Atlanta: CDC; 2020 (https://www.cdc.gov/coronavirus/2019-nCoV/hcp/index.html, accessed 15 May 2020).

22. Cochrane. Coronavirus (COVID-19) - Cochrane resources and news (https://www.cochrane.org/coronavirus-covid-19-cochraneresources-and-news\#healthcareworkers, accessed 15 May 2020).

23. Dashash M. Identifying and assessing competencies for an entry level graduate in the faculty of dentistry, Damascus university: Approaches, lessons learned and evidence provided. IJCMPR;2:708-711.

24. Dunn WR, Hamilton DD, Harden RM. Techniques of identifying competencies needed of doctors. Med Teach. 1985;7:15-25, doi: 10.3109/01421598509036787

25. Combining skills, attitude and knowledge into ability. (https://www.shutterstock.com/image-illustration/combining-skillsattitude-knowledge-into-ability-1258390324, accessed 15 May 2020.

26. Clerkship Directors in Emergency Medicine (CDEM). Introduction to the core competencies (https://www.saem.org/cdem/education/online-education/m3-curriculum/communication/introduction-to-the-core-competencies , accessed 12 July 2020).

27. The Royal College of Emergency Medicine (RCEM). Curriculum and assessment systems For training in emergency medicine, The Royal College of Emergency Medicine. London: RCEM; 2015 (https://www.gmc-uk.org//media/documents/RCEM_curriculum_05_03_15_for_August_2015_FINAL__AMENDED_05_06_15_.pdf_61270597.pdf, accessed 12 July 2020.

28. Penciner R, Woods RA, McEwen J, Lee R, Langhan T, Bandiera G, et al. Core competencies for emergency medicine clerkships: results of a Canadian consensus initiative. CJEM 2013;15:24-33.

29. Miller GE. The assessment of clinical skills/competence/performance. Acad Med. 1990;65 (9Suppl):S63-S67. doi:10.1097/oooo1888199009000-00045

30. Bajammal S, Zaini R, Abuznadah W, Al-Rukban M, Aly SM, Bokeret A, et al. The need for national medical licensing examination in Saudi Arabia. BMC Med Educ. 2008;8:53. https://doi.org/10.1186/1472-6920-8-53.

31. Huynh G, Nguyen TN, Tran VK, Vo KN, Vo VT, Pham LA. Knowledge and attitude toward COVID-19 among healthcare workers at District 2 Hospital, Ho Chi Minh City. Asian Pac J Trop Med. 2020;13:260-5.

32. Zhang M, Zhou M, Tang F, Wang Y, Nie H, Zhang L, et al. Knowledge, attitude, and practice regarding COVID-19 among healthcare workers in Henan, China. J Hosp Infect. 2020;105:183-187. https://doi.org/10.1016/j.jhin.2020.04.012

33. Shah S, McCann M, Yu C. Developing a national competency-based diabetes curriculum in undergraduate medical education: A Delphi study. Can J Diabetes. 2020;44:30-36.e2. doi:10.1016/j.jcjd.2019.04.019 